\title{
The Big Biosphere Party
}

\author{
J. T. Trevors • M. H. Saier Jr.
}

Received: 10 June 2008 / Accepted: 12 June 2008/Published online: 7 September 2008

(C) Springer Science + Business Media B.V. 2008

The big biosphere party continues, at least for the wealthier members of the planet's human population. Unfortunately this is not true for the economically disadvantaged two billion people who are plagued with continual suffering and premature death on a daily basis. The partiers continue to live in a world of denial and wishful thinking where unlimited human population growth spells the biosphere's demise. Driven by fear and insecurity as well as a desire for immediate comfort, our population continues to extract the remaining hydrocarbons from the Earth, spewing green house gases into our atmosphere and oceans.

Huge amounts of labor and money are extracted from individuals in the process known as "economic growth". This growth can most often be equated to exploitation of many driven by the greed of a few. Still, there are others, mostly in academic environments, who know that economic growth without regard to the environment that sustains us should

J. T. Trevors $(\bowtie)$

Department of Environmental Biology,

University of Guelph,

Guelph, ON N1G 2W1, Canada

e-mail: jtrevors@uoguelph.ca

M. H. Saier Jr.

Division of Biological Sciences,

University of California,

La Jolla,

San Diego, CA, USA

e-mail: saier@biomail.ucsd.edu have been terminated years ago. How can the big biosphere pollution party continue with world energy use already at capacity?

Many observations suggest that increases in energy production by another $50 \%$ will be required when 2030 arrives to provide for the growing population unless we change our ways drastically. However, it is not clear that we have enough oil OR atmosphere for this to actually happen. The determinants of this proposed increase are simply the expanding human population and a drive for economic growth. With more people and more pollution come more illness and suffering. Current daily oil consumption is estimated at 85 million barrels. The laws of thermodynamics dictates that this generates tremendous amounts of gaseous and particulate pollution and heat.

Yes, the party should be over. Our entire economy was build on inexpensive energy, and this resource no longer exists. Energy is now expensive, and use of fossil fuels causes immense pollution of our biosphere. Therefore, most consumer items are likely to be more expensive in the future. Even without environmental problems such as global warming, the absence of a large middle class with disposable income will prevent economic growth. The future will be about survival and sustainability. And the possibility of sustainability will required a dramatic reduction in the human population, with several billion fewer people on the planet. Industrialists who thrive on cheap labor can not continue to pursue reckless policies involving population 
increases. Yet this is not all; sustainability will also require decreased energy consumption and much less global pollution. The fundamental laws of thermodynamics rule our planet, not economics, politicians and governments. Military personnel, religious fanatics with irrational convictions and gangs of thugs, try as they may, will also fail. There will be no alternative but to protect the planet, or all will perish. Only rational morality and planetary responsibility can help.

It is obvious that some traditional partiers continue to party. They wishfully believe their offspring will have an excellent future if only they accumulate enough wealth. They do not realize that the "good life" will be impossible in a deteriorating world. Denial of reality is a fatal error made by many politicians and other influential people. Possibly, they do not understand the biological consequences of natural selection. They would benefit from an understanding of Biology.

We have no knowledge of the life span of our technological civilization. Pollution and human population growth are not our only challenges. We can not cast aside any of the challenges that must be confronted because of resource wars and conflicts. Our ever expanding and polluting agricultural efforts will be insufficient due to overpopulation and decreased arable land availability. Inadequate public health and affordable transportation will also contribute to our current downward slide. Education could help, but it is costly and takes time.
Conservation efforts will certainly be thwarted by poverty and greed. Extreme weather, droughts, floods, fires, and loss of our forests will all have to be factored in. All of these extremes will intensify with anthropogenic climate change. Exhaustion of the world's fisheries and our mineral and ore extraction capabilities together with our efforts to dispose of wastes will further hamper conservation attempts. Other problems will deal with potable and irrigation water which are already sorely depleted.

Are our modern democracies up to the challenges of the immediate future? Are the best minds being consulted and their ideas and plans being implemented? Clearly, the answers to these questions are likely to be negative. We do not have the luxury of time to solve these problems, and there is no indication that our governments are even contemplating the right approaches. The future looks bleak. In previous editorials we have suggested actions and solutions to help solve these problems. If only ONE action is take, let it be universal birth control funded by the wealthier nations of the world. That alone could make a huge difference, diminishing expansion of the current levels of human suffering. And of the various available approaches, implementation of universal birth control and abortion availability is probably the most feasible approach to a solution of our environmental crisis. Let us hope that the world will wake up and implement this and other essential solutions before it is too late. 